\title{
Harnessing the power of microbial genomics for exploring exceptions and shifting perceptions
}

\author{
Naomi L. Ward ${ }^{1,2,3 *}$ and Martin G. Klotz ${ }^{4,5}$ \\ 1 Department of Molecular Biology, University of Wyoming, Laramie, WY, USA \\ 2 Department of Botany, University of Wyoming, Laramie, WY, USA \\ 3 Program in Ecology, University of Wyoming, Laramie, WY, USA \\ ${ }^{4}$ Department of Biology, University of Louisville, Louisville, KY, USA \\ ${ }^{5}$ Department of Microbiology and Immunology, University of Louisville, Louisville, KY, USA \\ *Correspondence: n/ward@uwyo.edu
}

The launch of "Frontiers in Evolutionary and Genomic Microbiology" marks 15 years since generation of the first genome sequence from a free-living organism (Fleischmann et al., 1995). In this relatively short time, microbial genome sequencing has allowed enormous advances in our understanding of the genomic basis of microbial life, and it is difficult to think of a sub-field of microbiology that has not been profoundly affected. The volume and diversity of data available from projects that are completed or ongoing $(5,465$ bacterial genomes and 209 archaeal genomes, according to www.genomesonline.org, accessed December 21,2010) presents both opportunities and challenges. One of the most exciting challenges is how to best exploit genomic data to understand the exceptions of bacterial and archaeal biology. These exceptions conflict with accepted hypotheses and theories, and challenge the "rules" that we presently teach from microbiology textbooks. They also provide opportunities to uncover new commonalities and interactions between and within the three domains of life.

Such exceptions have sometimes been recognized for many years, but the availability of a new genome sequence can serve as a springboard for new experimental work. The results of this work can demonstrate a functional role for the exception and, in some cases, bring about a shift in perceptions. Many examples could be cited, but rather than provide an exhaustive list, the authors beg the indulgence of readers to focus on a personal area of interest - the cell biology and evolutionary history of members of the Planctomycetes-VerrucomicrobiaChlamydiae (PVC) superphylum (Wagner and Horn, 2006). Several members of this group have a common cell plan that features a ribosome-free paryphoplasm separated from a ribosome-containing riboplasm by an intracellular membrane (Fuerst, 2005; Lee et al., 2009). Planctomycete bacteria exhibit additional intracellular complexity, such as the double-layered membrane system that surrounds the condensed genomic DNA of Gemmata obscuriglobus (Fuerst and Webb, 1991) or the anammoxosome (anaerobic ammonia-oxidizing compartment) in the Brocadiaceae family (Jetten et al., 2001). Both of these findings challenge the validity of restricting the terms "nucleus" and "organelle," respectively, to the domain Eukarya. The availability of genome sequences from members of the PVC superphylum has allowed creative computational and experimental work to demonstrate - uniquely within the domain Bacteria - the presence of protein structures that resemble eukaryotic membrane coat proteins (Santarella-Mellwig et al., 2010). A representative of these coat-like proteins was localized to paryphoplasmic vesicles in G. obscuriglobus (Santarella-Mellwig et al., 2010), and, most remarkably, these same vesicles were found to receive proteins endocytosed by the Gemmata cell (Lonhienne et al., 2010). Thus the availability of PVC superphylum genomes and subsequent experiments allowed demonstration of commonalities between eukaryotic and bacterial cellular trafficking, and of an exception to the rule of endocytosis as a stereotypically eukaryotic trait. The G. obscuriglobus genome sequence also provided a springboard for the discovery of sterols in this organism (Pearson et al., 2003), one of only a handful of examples in the Bacteria for another characteristic eukaryotic property. It remains to be seen whether the sterols of Gemmata contribute to the structure of its complex endomembrane system. If so, this would provide an interesting parallel to the presence of other unusual planctomycete molecules (the ladderanes) in the anammoxosome of the anammox planctomycetes (Sinninghe Damsté et al., 2002).
These genome-enabled findings in the PVC superphylum have naturally spurred other efforts to use high-throughput computational analyses to better understand the evolutionary history and uncover the genomic basis of unusual aspects of PVC member biology. Because of the relatively large phylogenetic distances separating members of the PVC phyla, there is an urgent need for closing the gaps with more genome sequences. However, while we wait for these sequences to be generated, it is worthwhile to consider novel analytical approaches that can accommodate the phylogenetic distances of the currently available PVC genomes. Whole-genome scans for positive Darwinian selection are widely used to detect evolution of genome novelty, but commonly used methods (e.g., evaluation of non-synonymous to synonymous substitution rate ratio across evolutionary lineages) are sensitive to saturation of synonymous sites and thus cannot be used to study evolution of distantly related organisms. Such challenges stimulate the development of alternative methodologies such as the analysis of indel (insertion/deletion) events, which occur less frequently than amino acid replacements, accumulate more slowly, and generate functional changes through positive selection. They thus can be employed to characterize evolution of diverged organisms such as members of the PVC superphylum (Kamneva et al., 2010). While these new methodologies have been successfully developed for characterization of this particular group of organisms, they could be applied to any of the relatively newly described phyla where cultured representatives and genomes are sparse, and phylogenetic distances are large.

Arguably the most exciting genome-based insights into microbial ecology have been obtained from metagenomics, the analysis of entire microbial communities (Rondon 
et al., 2000). We can turn to another favorite microbial group, the nitrifiers (aerobic oxidizers of ammonia to nitrate) for an example of how metagenomic analysis has shifted our perception of the "key players" in an ecologically important process. Cultured members of the genera Nitrosomonas, Nitrosospira, and Nitrobacter were thought to be the major contributors to nitrification in the natural environment. However, metagenomic analysis has revealed the importance of other bacterial nitrite oxidizers not yet available in axenic culture (Lücker et al., 2010), and novel ammonia-oxidizing archaea (Treusch et al., 2004, 2005; Francis et al., 2005; Leininger et al., 2006; Reigstad et al., 2011). The combination of metagenomics and classical isolation techniques have most recently led to a significant expansion of the former (Lebedeva et al., 2011; Spieck and Lipski, 2011). The latter have now been shown to be a distinct phylum of organisms that perform ammonia oxidation with a novel gene inventory, higher substrate affinity, and different pathways than known for the ammonia-oxidizing bacteria, and also to be the dominant ammonia-oxidizers in the majority of environments where nitrification occurs (Könneke et al., 2005; Prosser and Nicol, 2008; Martens-Habbena et al., 2009; Schleper and Nicol, 2010; Spang et al., 2010). Ecological insight into the function of microbes "closer to home" has also been gained through recent forays into metagenomics of the human microbiome. Among these, metagenomic analysis of the gastrointestinal microbiome has revealed a tremendous diversity of carbohydrate-active enzymes presumed to be responsible for the catabolism of dietary fiber (Li et al., 2009; Turnbaugh et al., 2010). A recent study (Tasse et al., 2010) demonstrated that a targeted functional metagenomics approach could detect carbohydrate-active enzymes from organisms representing a minority of the dominant gut bacteria. Such enrichment strategies provide helpful models for addressing one of the major challenges of metagenomic studies - elucidating the structure-function relationships of microbial communities and (where hosts exist) how those relationships affect host biology.

The few examples discussed here illustrate the interesting paths genome-based research can follow when computational and experimental approaches are creatively combined, and when the realities of the structure of the bacterial tree drive the development of new bioinformatic tools. These combinations can (or could) feature some of the many new genome-based methodologies ranging from synthetic genomics (Gibson et al., 2010) and single-cell environmental genomics (Ishoey et al., 2008), to genomebased microbial systematics and taxonomy (Konstantinidis and Tiedje, 2005) and powerful functional genomics screens that explore host-pathogen relationships in a high-throughput fashion (Waterfield et al., 2008). We can therefore expect that as we continue to gain unprecedented insight into the gene inventory underlying the biology of bacteria and archaea (both cultured and currently uncultured) we will also discover creative new ways to harness the power of microbial genomics to understand exceptions and challenge current perceptions. "Frontiers in Evolutionary and Genomic Microbiology" provides an ideal publishing platform to describe both novel findings and novel approaches, and we look forward to receiving both types of contributions.

\section{ACKNOWLEDGMENTS}

This work was supported in part by awards MCB-0920667(NLW), EPS-0447681 (NLW) and MCB-0948202 (MGK) from the United States National Science Foundation and incentive funds provided by the UofL EVPR office (MGK).

\section{REFERENCES}

Fleischmann, R. D., Adams, M. D., White, O., Clayton, R. A., Kirkness, E. F., Kerlavage, A. R., Bult, C. J., Tomb, J.-F., Dougherty, B. A., Merrick, J. M., McKenney, K., Sutton, G., FitzHugh, W., Fields, C., Gocayne, J. D. Scott, J., Shirley, R., Liu, L. I., Glodek, A., Kelley, J. M., Weidman, J. F., Phillips, C. A., Spriggs, T., Hedblom, E., Cotton, M. D., Utterback, T. R., Hanna, M. C., Nguyen, D. T., Saudek, D. M., Brandon, R. C., Fine, L. D., Fritchman, J. L., Fuhrmann, J. L., Geoghagen, N. S. M., Gnehm, C. L., McDonald, L. A., Small, K. V., Fraser, C. M., Smith, H. O., and Venter, J. C. (1995). Whole-genome random sequencing and assembly of Haemophilus influenzae Rd. Science 269, 496-512.

Francis, C. A., Roberts, K. J., Beman, J. M., Santoro, A E., and Oakley, B. B. (2005). Ubiquity and diversity of ammonia-oxidizing archaea in water columns and sediments of the ocean. Proc. Natl. Acad. Sci. U.S.A. $102,14683-14688$.

Fuerst, J. A. (2005). Intracellular compartmentation in planctomycetes. Annu. Rev. Microbiol. 59, 299-328.

Fuerst, J.A., and Webb, R. I. (1991). Membrane-bounded nucleoid in the eubacterium Gemmata obscuriglobus. Proc. Natl. Acad. Sci. U.S.A. 88, 8184-8188.

Gibson, D. G., Glass, J. I., Lartigue, C., Noskov, V. N., Chuang, R., Algire, M. A., Benders, G. A., Montague, M. G., Ma, L., Moodie, M. M., Merryman, C., Vashee, S., Krishnakumar, R., Assad-Garcia, N.,
Andrews-Pfannkoch, C., Denisova, E. A., Young, L., Qi, Z. Q., Segall-Shapiro, T. H., Calvey, C. H., Parmar, P. P., Hutchison, C. A. 3rd, Smith, H. O., and Venter, J. C. (2010). Creation of a bacterial cell controlled by a chemically synthesized genome. Science 329, 52-56.

Ishoey, T., Woyke, T., Stepanauskas, R., Novotny, M., and Lasken, R. S. (2008).Genomic sequencing of single microbial cells from environmental samples. Curr Opin. Microbiol. 11, 198-204.

Jetten, M. S., Wagner, M., Fuerst, J., van Loosdrecht, M., Kuenen, G., and Strous, M. (2001). Microbiology and application of the anaerobic ammonium oxidation (“anammox") process. Curr. Opin. Biotechnol. 12, 283-288.

Kamneva, O. K., Liberles, D. A., and Ward, N. L. (2010). Genome-wide influence of indel substitutions on evolution of bacteria of the PVC super-phylum, revealed using a novel computational method. Genome Biol. Evol. 2, 870-886.

Könneke, M., Bernhard, A. E., de la Torre, J. R., Walker, C. B., Waterbury, J. B., and Stahl, D.A. (2005). Isolation of an autotrophic ammonia-oxidizing marine archaeon. Nature 437, 543-546.

Konstantinidis, K. T., and Tiedje, J. M. (2005). Genomic insights that advance the species definition for prokaryotes. Proc. Natl. Acad. Sci. U.S.A. 102, 2567-2572.

Lebedeva, E. V., Off, S., Zumbrägel, S., Kruse, M., Shagzhina, A., Lücker, S., Maixner, F., Lipski, A., Daims, H., and Spieck, E. (2011). Isolation and characterization of a moderately thermophilic nitrite-oxidizing bacterium from a geothermal spring. FEMS Microbiol. Ecol. doi: 10.1111/j.1574-6941.2010.01006.x

Lee, K., Webb, R. I., Janssen, P. H., Sangwan, P., Romeo, T., Staley, J. T., and Fuerst, J. A. (2009). Phylum Verrucomicrobia representatives share a compartmentalized cell plan with members of bacterial phylum Planctomycetes. BMC Microbiol. 9, 5. doi: 10.1186/1471-2180-9-5

Leininger, S., Urich, T., Schloter, M., Schwark, L., Qi, J., Nicol, G. W., Prosser, J. I., Schuster, S. C., and Schleper, C. (2006). Archaea predominate among ammoniaoxidizing prokaryotes in soils. Nature 442, 806-809.

Li, L., McCorkle, S. R., Monchy, S., Taghavi, S., and van derLelie, D. (2009). Bioprospecting metagenomes: glycosyl hydrolases for converting biomass. Biotechnol. Biofuels 2, 10.

Lonhienne, T. G. A., Sagulenko, E., Webb, R. I., Lee, K., Franke, J., Devos, D. P., Nouwens, A., Carroll, B. J., and Fuerst, J. A. (2010). Endocytosis-like protein uptake in the bacterium Gemmata obscuriglobus. Proc. Natl. Acad. Sci. U.S.A. 107, 12883-12888.

Lücker, S., Wagner, M., Maixner, F., Pelletier, E., Koch, H., Vacherie, B., Rattei, T., SinningheDamsté, J. S., Spieck, E., Le Paslier, D., and Daims, H. (2010). A Nitrospira metagenome illuminates the physiology and evolution of globally important nitrite-oxidizing bacteria. Proc. Natl. Acad. Sci. U.S.A. 107, 13479-13484.

Martens-Habbena, W., Berube, P. M., Urakawa, H., de la Torre, J. R., and Stahl, D. A. (2009). Ammonia oxidation kinetics determine niche separation of nitrifying archaea and bacteria. Nature 461, 976-979.

Pearson, A., Budin, M., and Brocks, J. J. (2003). Phylogenetic and biochemical evidence for sterol synthesis in the bacterium Gemmata obscuriglobus. Proc. Natl. Acad. Sci. U.S.A. 100, 15352-15357.

Prosser, J. I., and Nicol, G. W. (2008). Relative contributions of archaea and bacteria to aerobic ammonia 
oxidation in the environment. Environ. Microbiol. 10, 2931-2941.

Reigstad, L. J., Bartossek, R., and Schleper, C. (2011). "Preparation of high-molecular-weight DNA and metagenomic libraries from soils and hot springs," in Methods in Enzymology, Vol. 486, Part B, eds M. G. Klotz and L. Y. Stein (Oxford: Academic Press/Elsevier Inc.). ISBN: 978-0-12-381294-0. (in press).

Rondon, M. R., August, P. R., Bettermann, A. D., Brady, S. F., Grossman, T. H., Liles, M. R., Loiacono, K. A., Lynch, B. A., MacNeil, I. A., Minor, C., Tiong, C. L., Gilman, M., Osburne, M. S., Clardy, J., Handelsman, J., and Goodman, R. M. (2000). Cloning the soil metagenome: a strategy for accessing the genetic and functional diversity of uncultured microorganisms. Appl. Environ. Microbiol. 66, 2541-2547.

Santarella-Mellwig, R., Franke, J., Jaedicke, A., Gorjanacz, M., Bauer, U., Budd, A., Mattaj, I. W., and Devos, D. P. (2010). The compartmentalized bacteria of the planctomycetes-verrucomicrobia-chlamydiae superphylum have membrane coat-like proteins. PLoS Biol. 8, e1000281. doi: 10.1371/journal.pbio.1000281

Schleper, C., and Nicol, G. W. (2010). Ammonia-oxidising archaea - physiology, ecology and evolution. Adv. Microb. Physiol. 57, 1-41.

Sinninghe Damsté, J. S., Strous, M., Rijpstra, W. I. C., Hopmans, E. C., Geenevasen, J. A. J., van Duin, A. C. T., van Niftrik, L. A., and Jetten, M. S. (2002). Linearly concatenated cyclobutane lipids form a dense bacterial membrane. Nature 419, 708-712.
Spang, A., Hatzenpichler, R., Brochier-Armanet, C., Rattei, T., Tischler, P., Spieck, E., Streit, W., Stahl, D. A., Wagner, M., and Schleper, C. (2010). Distinct gene set in two different lineages of ammonia-oxidizing archaea supports the phylum Thaumarchaeota. Trends Microbiol. 18, 331-340.

Spieck, E., and Lipski, A. (2011). "Cultivation, growth physiology, and chemotaxonomy of nitrite-oxidizing bacteria," in Methods in Enzymology, Vol. 486, Part A, ed. M. G. Klotz (Oxford: Academic Press/Elsevier Inc.), 109-130.

Tasse, L., Bercovici, J., Pizzut-Serin, S., Robe, P., Tap, J., Klopp, C., Cantarel, B. L., Coutinho, P. M., Henrissat, B., Leclerc, M., Doré, J., Monsan, P., Remaud-Simeon, M., and Potocki-Veronese, G. (2010). Functional metagenomics to mine the human gut microbiome for dietary fiber catabolic enzymes. Genome Res. 20, 1605-1612.

Treusch, A. H., Kletzin, A., Raddatz, G., Ochsenreiter, T., Quaiser, A., Meurer, G., Schuster, S. C., and Schleper, C. (2004). Characterization of large-insert DNA libraries from soil for environmental genomic studies of archaea. Environ. Microbiol. 6, 970-980.

Treusch, A. H., Leininger, S., Kletzin, A., Schuster, S. C., Klenk, H., and Schleper, C. (2005). Novel genes for nitrite reductase and Amo-related proteins indicate a role of uncultivated mesophilic crenarchaeota in nitrogen cycling. Environ. Microbiol. 7, 1985-1995.

Turnbaugh, P. J., Quince, C., Faith, J. J., McHardy, A. C., Yatsunenko, T., Niazi, F., Affourtit, J., Egholm, M., Henrissat, B., Knight, R., and Gordon, J. I. (2010).
Organismal, genetic, and transcriptional variation in the deeply sequenced gut microbiomes of identical twins. Proc. Natl. Acad. Sci. U.S.A. 107, 7503-7508.

Wagner, M., and Horn, M. (2006). The Planctomycetes, Verrucomicrobia, Chlamydiae and sister phyla comprise a superphylum with biotechnological and medical relevance. Curr. Opin. Biotechnol. 17, 241-249.

Waterfield, N. R., Sanchez-Contreras, M., Eleftherianos, I., Dowling, A., Yang, G., Wilkinson, P., Parkhill, J., Thomson, N., Reynolds, S.E., Bode, H. B., Dorus, S., and Ffrench-Constant, R.H. (2008). Rapid virulence annotation (RVA): identification of virulence factors using a bacterial genome library and multiple invertebrate hosts. Proc. Natl. Acad. Sci. U.S.A. 105, 15967-15972.

Received: 21 December 2010; accepted: 22 December 2010; published online: 04 January 2011.

Citation: Ward NL and Klotz MG (2011) Harnessing the power of microbial genomics for exploring exceptions and shifting perceptions. Front. Microbio. 1:146. doi: 10.3389/ fmicb.2010.00146

This article was submitted to Frontiers in Evolutionary and Genomic Microbiology, a specialty of Frontiers in Microbiology.

Copyright (C) 2011 Ward and Klotz. This is an open-access article subject to an exclusive license agreement between the authors and the Frontiers Research Foundation, which permits unrestricted use, distribution, and reproduction in any medium, provided the original authors and source are credited. 